International Journal of Linguistics, Literature and Translation

ISSN: 2617-0299 (Online); ISSN: 2708-0099 (Print)

DOI: $10.32996 /$ ijllt

Journal Homepage: www.al-kindipublisher.com/index.php/ijltt

IJLLT

\title{
Student Attitude Towards the Application of Conceptual Metaphors to Teaching English Idioms
}

\author{
Thai Bao Ngoc Pham \\ Lecturer, Faculty of English Linguistics and Literature, University of Social Sciences and Humanities, Ho Chi Minh City, Vietnam \\ $\square$ Corresponding Author: Thai Bao Ngoc Pham, E-mail: phamthaibaongoc@hcmussh.edu.vn
}

\begin{abstract}
ARTICLE INFORMATION ABSTRACT
Received: 15 September 2021

Accepted: 15 October 2021

Published: 30 October 2021

DOI: $10.32996 /$ ijllt.2021.4.10.15

\section{KEYWORDS}

Attitude, CM-inspired instruction, conceptual metaphors, idioms

Contrary to the traditional view of idioms, cognitive linguists have demonstrated that the nature of idioms is not arbitrary and rote memorization is not the only way to learn them. The discovery of conceptual metaphor (CM) and its application to teaching idiomatic language in EFL has opened up a new path to more systematic and perceptive learning. However, the learners' attitudes towards the employment of conceptual metaphors have yet to be thoroughly explored. To address this issue, the current study aimed to investigate the attitudes of 106 Vietnamese university students towards the CM-inspired instruction after a five-week treatment. Two research instruments were employed in this study: an attitudinal questionnaire and a semistructured interview. The results of the study reveal that the $\mathrm{CM}$-inspired instruction received positive feedback from the students, though the instruction itself exposed some shortcomings that need to be dealt with. To overcome its shortcomings, actual pictures and activities for structural elaboration are proposed to be used concurrently with the CM-inspired instruction.
\end{abstract}

\section{Introduction}

Idioms have been extensively used in all spoken and written genres of discourse, ranging from everyday conversation and journalism to more formal contexts, such as lectures, academic essays, and business reports (Brenner, 2003; O'Dell \& McCarthy, 2010). It is estimated that there are more than 10,000 idiomatic expressions in English and new idioms are still created in different forms of discourse (Brenner, 2003). Among different types of formulaic sequences, idioms are an integral component (Simpson \& Mendis, 2003; O'Dell \& McCarthy, 2010) and the mastery of these expressions is part of communicative competence (Celce-Murcia, 2008).

Despite the increasingly significant number of idioms in English and their importance in developing learner proficiency, idioms are frequently ignored in EFL classrooms (Irujo, 1986; Tran, 2013). Because idioms were often believed to have arbitrary meanings and their component words tend to have fixed or syntactically restricted order (Fernando, 1996), rote memorization was considered as the only way to learn these expressions (Boers, Eyckmans, \& Stengers, 2007). However, since the 1980s, cognitive linguists have ascertained that idioms are not arbitrary and it is a conceptual metaphor that is the motivation behind the figurative meanings of several idiomatic expressions (Lakoff \& Johnson, 1980; Kövecses, 2002). This finding has been an inspiration for several studies on the effect of conceptual metaphors on idiom acquisition (Khoshniyat \& Dowlatabadi, 2014; Kartal \& Uner, 2017; Pérez, 2018; Chen, 2019; Pham, 2019; Shan, 2020). These studies have revealed that conceptual metaphors have a significant effect on EFL learners' comprehension and retention of English idioms, opening up an original pathway to more systematic and perceptive learning.

However, most previous studies have directed their attention to the student's performance after the adoption of conceptual metaphors in the instruction stage but had a little discussion on their attitudes towards this cognitive approach, which is also a very important factor in determining the practicality of the method. As a descendant, this study has carefully examined this aspect as an attempt to fill in the gap in the literature on applying conceptual metaphors to teaching and learning idioms. The aim of this

Copyright: (c) 2021 the Author(s). This article is an open access article distributed under the terms and conditions of the Creative Commons Attribution (CC-BY) 4.0 license (https://creativecommons.org/licenses/by/4.0/). Published by Al-Kindi Centre for Research and Development, London, United Kingdom. 
study can be addressed through the following research question: What are the students' attitudes towards the application of conceptual metaphors to teaching idioms?

\section{Literature Review}

\subsection{Conceptual metaphor}

In the view of cognitive linguistics (CL), metaphor is not considered as a poetic fancy device used in the rhetorical style; it is, in fact, "pervasive in everyday life, not just in language, but in thought and action" (Lakoff \& Johnson, 1980, p. 3). The major function of metaphor is to assist the comprehension of one concept in terms of another, typically a more abstract concept in terms of a more concrete or physical concept (Kövecses, 2002).

When cognitive linguists talk about metaphor, they do not refer to the linguistic expression as the traditional view does, but to the cognitive mapping, it represents. Specifically, conceptual metaphor is defined as a mapping across conceptual domains and each mapping is "a systematic set of correspondences" that exist between constituent elements of the source and the target domain (Kövecses, 2002, p. 7). According to Lakoff (1993), a conceptual metaphor can be expressed as TARGET-DOMAIN IS SOURCEDOMAIN, or alternatively, TARGET-DOMAIN AS SOURCE-DOMAIN (p. 207). For each underlying conceptual metaphor, there may be several metaphorical linguistic expressions (e.g. words, phrases, or sentences) which are "the surface realization of such a crossdomain mapping" (Lakoff, 1993, p. 203). The following table provides an example of the mapping of LIFE AS A JOURNEY and its linguistic expressions.

Table 1. Ontological correspondences of LIFE AS A JOURNEY

\begin{tabular}{|c|c|c|}
\hline LIFE IS A JOURNEY & & \\
\hline Source domain: A JOU & $\rightarrow$ Target domain: LIFE & Metaphorical expressions \\
\hline a traveler & the person leading a life & - Getting her Ph.D. was a big landmark in her life. \\
\hline destinations & his/her purposes & - He knows where he's headed and will never let anyone \\
\hline routes & the means for achieving purposes & get in his way. \\
\hline impediments to travel & difficulties in life & - You can't just go through life with your eyes closed! You \\
\hline the distance traveled & progress & can't go far in life by that way. \\
\hline crossroads & choices in life & $\begin{array}{l}\text { - After earning my degree, I'm at a crossroads. I need to } \\
\text { figure out which direction my life should take. }\end{array}$ \\
\hline
\end{tabular}

(adapted from Lakoff \& Turner, 1989)

The mapping here is tightly structured. It includes ontological correspondences, according to which constituent elements in the domain of life (e.g., a traveler, destinations, routes, impediments to travel, etc.) correspond systematically to constituent elements in the domain of a journey (the person leading a life, his/her purposes, the means for achieving purposes, difficulties in life, etc.). Such correspondences permit native speakers to reason about life by using the knowledge they use to reason about journeys, and this process usually takes place unconsciously and the speaker and listener produce and understand the metaphorical expressions without any effort.

\subsection{Using conceptual metaphors to teach English idioms}

In recent years, there has been an increasing amount of literature on the employment of conceptual metaphors in teaching vocabulary in general and idiomatic expressions in particular. Arguments for the adoption of conceptual metaphors include claims that this technique can help the learners enhance their understanding and retention of the target language, explore the link between language and culture and boost their confidence in learning $L 2$ vocabulary in a more insightful way instead of relying on rote memorization (Boers \& Lindstromberg, 2008; Doiz \& Elizari, 2013). Several empirical studies have proved that metaphor awareness can help enhance the comprehension, retention, and even production of idiomatic expressions (Khoshniyat \& Dowlatabadi, 2014; Kartal \& Uner, 2017; Pérez, 2018; Chen, 2019; Pham, 2019; Shan, 2020). In addition, a variety of CM-related activities have been designed and step-by-step guidelines on how to apply conceptual metaphors to teaching idioms have also been proposed to ensure that $L 2$ learners can play an active role in their idiom acquisition with conceptual metaphors as an organizer and motivator of English idiomatic expressions (Pham, 2017; Pham, 2019; Upadhaya \& Sudharshana, 2021). However, so far, there seems to be little attitudinal research to investigate the students' opinions, feelings, and reactions to the application of conceptual metaphors in the EFL learning environment, which is also a significant factor in determining the feasibility of this cognitive method.

According to Kömür and Çimen (2009), the employment of conceptual metaphors in teaching English idioms appears to have a strong impact on the classroom environment in general and student attitude in particular. In their study, 32 Turkish students were guided to learn 38 idioms with metaphorically enriched activities. The result from the open-ended itemized questionnaire suggested that highlighting conceptual metaphors in teaching idioms could make an important contribution in creating an 
enjoyable and interactive classroom atmosphere, increasing the learners' autonomy and facilitating their progress both in receptive and productive sides. This method also allows the students to learn more about the English language and develop their cultural awareness. However, there is still considerable uncertainty with regard to the result of this research. In addition to the metaphorically-enriched activities, the teacher in Kömür and Çimen (2009) used a variety of communicative activities and other teaching strategies, such as brainstorming, role plays, negotiating on the meaning, personalization, etc. to attract the students' attention, promote higher-order thinking skills, and create a strong motivation for them to learn the target idiomatic expressions. Thus, it is uncertain whether the Turkish respondents' positive feelings as reported from the research were due to the CM-related activities or other communicative activities that they engaged in during the lesson. Besides, the questionnaire in this study appeared inadequate with only one open-ended question, and therefore it seemed to be unable to examine different aspects of student attitude towards the use of conceptual metaphors in teaching idioms.

Similar to Kömür and Çimen (2009), Wang (2020) found that EFL learners' better awareness of idioms and their etymology thanks to the cognitive-linguistics-informed approach results in their positive attitudes towards learning idioms. In the study, 25 Chinese students were instructed to learn 21 English figurative idioms with the CL-informed approach within one hour. One week later, a semi-structured interview was conducted with these students to examine their strategies to deal with unfamiliar idioms, their methods to memorize these expressions, their actual experience with idioms and idiom etymology, and their general attitudes towards learning and using idioms. The results showed that more than half of the students were willing to learn more about L2 idioms and several of them were interested in using idioms if they had the opportunity to practice and use them. It could be seen that the questions in the interview do not simply focus on student attitude but they cover different aspects of idiom learning; even the two questions related to the students' experience and attitude were rather general as the students were simply asked about their attitudes towards learning and using the taught idioms as well as idioms in general and therefore their attention was not directed to the use of the $\mathrm{CL}$-informed approach to teaching and learning idioms. In other words, the findings of the study did not reveal whether or not the students had positive attitudes towards the cognitive approach. Although some students did mention that they would search for etymological information to better understand and remember the meaning of the new idioms, this does not necessarily mean that the other students did not find this method interesting and useful. Moreover, the experiment was performed in only one short lesson and the sample size seemed rather limited, which might prevent the researcher from drawing a reliable conclusion about the effect of the cognitive approach on the students' performance and learning attitude. In addition, although etymological elaboration and CM-related instruction are largely related in terms of cognitive linguistics, the student attitude towards etymology and conceptual metaphors may not be similar.

Though the use of conceptual metaphors is proved to be beneficial to idiom acquisition, little is known about what students actually believe and how they actually feel and react to this cognitive approach which is also vital to the success of their acquisition of idiomatic expressions in the long term. Although there are a few studies related to this issue (Kömür \& Çimen, 2009; Wang, 2020), they both show limitations on the sample size, the number of idioms taught in the experiment, and especially the survey or the number of interview questions. This study is an attempt to fill this gap in the literature by improving the research methodology and designing a detailed questionnaire in order to thoroughly investigate different aspects of student attitude towards the employment of conceptual metaphors to teaching idioms.

\section{Methodology 3.1 Participants}

This research was conducted at the Faculty of English Linguistics and Literature, at the University of Social Sciences and Humanities, Vietnam National University, Ho Chi Minh City, in the academic year 2020-2021. Initially, there were 112 English-majored freshmen who volunteered to participate in the research. This was convenience sampling since only the students who were taking the Grammar course taught by the researcher were invited to participate in the study. The reason for the selection of these students was that the teaching of idioms could contribute to the course syllabus. Specifically, in addition to different English grammatical issues, the students in the Grammar course were required to learn about word combinations, including collocations, phrasal verbs, and idiomatic expressions. Moreover, the English-majored freshmen had to take different courses in English language skills and the ability to understand and use idiomatic language accurately is one of the criteria to assess their performance; therefore, their participation in the experiment was useful not only for the Grammar course but also for other courses they were taking at the time and the development of their English skills in general.

During the teaching stage, however, four students did not attend at least four lessons out of the total five idiom lessons, so they were excluded from the study. After the teaching stage, questionnaires were distributed to the participants via email due to the impact of the Covid-19 pandemic. A total of 108 copies were returned; 106 copies were eligible. The description of the participants is summarized in Table 2. 
Table 2. Demographic characteristics of the participants

\begin{tabular}{|l|l|l|l|}
\hline \multirow{2}{*}{ Number of students } & Raw count & Percentage \\
\cline { 2 - 4 } Gender & Male & 106 & $100 \%$ \\
\cline { 2 - 4 } & Female & 15 & $14.2 \%$ \\
\hline \multirow{2}{*}{ Age } & $17-18$ & 91 & $85.8 \%$ \\
\cline { 2 - 4 } & More than 18 & 102 & $96.2 \%$ \\
\hline \multirow{2}{*}{$\begin{array}{l}\text { English } \\
\text { Proficiency }\end{array}$} & B1 (Intermediate) & 4 & $3.8 \%$ \\
\cline { 2 - 4 } & B2 (Upper-intermediate) & 34 & $32.1 \%$ \\
\cline { 2 - 4 } & C1 (Advanced) & 69 & $65.1 \%$ \\
\hline
\end{tabular}

\subsection{Teaching materials and the teaching process}

Ten conceptual metaphors were selected for the teaching stage, including HAPPY IS UP and SAD IS DOWN, ANGER IS HEATED FLUID IN A CONTAINER and ANGER IS FIRE, LIFE IS A JOURNEY and LIFE IS A GAMBLING GAME, RELATIONSHIP IS A JOURNEY and RELATIONSHIP IS A LIVING ORGANISM, BUSINESS IS WAR and AN ORGANIZATION IS A GARDEN, together with 60 idioms as the surface realization of these conceptual metaphors. The numbers of conceptual metaphors and idioms taught in each lesson were 2 and 11-13, respectively. The lessons were provided to the students for five weeks in a row. There was one lesson per week, which last about 45 minutes. In fact, each lesson about idiomatic language was given right after the grammar lesson within one class meeting for the students' convenience to ensure that they did not have to attend the researcher's class twice a week. There was one extra 4-hour class meeting at the end of the course to compensate for the time when the students participated in the teaching experiment and therefore did not have enough practice on certain grammatical points.

Throughout the five lessons in the teaching stage, the researcher followed the five-step procedure proposed in Pham (2019), which includes: (1) introducing the notion of conceptual metaphor, (2) activating the source domain vocabulary, (3) explaining the ontological mappings of conceptual metaphors, (4) guide learners to apply conceptual metaphors to interpret idiom meaning, and (5) refine or rectify their interpretations, in order to develop the students' metaphor awareness and guide them to apply conceptual metaphors to learning idioms (p. 162). Firstly, the researcher introduced to the students what conceptual metaphors are and how pervasive they are in human language and thought. This introduction was presented only in the initial lesson; the following lessons skipped this step and began with step two. The topic of the target idioms was mentioned and groups of idioms were given to the students in the handout. In order to help the students understand the abstract meaning of idioms, the researcher started from their physical or literal meaning. In other words, the source domain was activated via reviewing the literal meaning of the constituent words in the target idioms. Then, in the third step, the researcher explicitly explained the correspondence between source and target domains, going from concrete and familiar phenomenon such as heated fluid or fire to abstract concepts like anger. Then, the students were encouraged to apply the knowledge of the conceptual metaphors to interpret the figurative meanings of the target idioms which had already been grouped under related conceptual metaphors. Upon their meaning guessing, the researcher provided feedback and correction to ensure that all the students had noted down the correct meanings of the idiomatic phrases.

\subsection{Research instruments}

Two instruments employed in this study were questionnaires and in-depth interviews.

\subsubsection{Questionnaire}

The questionnaire consists of 30 items, covering three sections: (A) the respondents' background information, (B) their attitudes towards the application of conceptual metaphors to teaching idioms, and (C) their suggestions for improving this cognitive approach. The concept of attitude is complicated, and a wide variety of definitions have been suggested to capture its essence. According to Gardner (1985), one's attitude is "an evaluative reaction to some referent or attitude object, inferred on the basis of the individual's beliefs or opinions about the referent" (p. 9). Zimbardo and Ebbesen (1970) even divided attitude into three measurable components, i.e. affective, cognitive, and behavioral. While the affective component involves "a person's evaluation of, liking of, or emotional response to some object or person", the cognitive component is understood as "a person's beliefs about, or factual knowledge of, the object or person" (Zimbardo \& Ebbesen, 1970, p. 7). The behavioral component, as its name suggests, is reflected in "the person's overt behavior directed toward the object or person" (ibid.). Following this three-fold definition, in the present study, the students' attitudes toward the CM-inspired instruction consisted of (a) their opinions about the benefits and drawbacks of applying conceptual metaphors to teaching idioms (cognitive aspect), (b) their feelings toward the CM-inspired instruction (affective aspect), and (c) their reactions to the instruction (behavioral aspect). The following table presents a summary of the questionnaire construct. 
Table 3. Distribution of the questions in the attitudinal questionnaire

\begin{tabular}{|c|c|c|c|c|}
\hline \multirow{2}{*}{\multicolumn{2}{|c|}{$\begin{array}{l}\text { Main themes } \\
\text { Demographic information }\end{array}$}} & \multirow{2}{*}{\multicolumn{2}{|c|}{$\begin{array}{l}\text { Sub-sections } \\
\text { Gender, age, language proficiency }\end{array}$}} & Items \\
\hline & & & & A. $1-$ A.4 \\
\hline \multirow{9}{*}{$\begin{array}{l}\text { Attitudes } \\
\text { towards the } \\
\text { application } \\
\text { of } \\
\text { conceptual } \\
\text { metaphors to } \\
\text { teaching } \\
\text { idioms }\end{array}$} & \multirow[b]{2}{*}{ Cognition } & \multirow{2}{*}{$\begin{array}{l}\text { Opinions about the benefits } \\
\text { and drawbacks of CM- } \\
\text { inspired instruction }\end{array}$} & Benefits & B.1.1 - B.1.9 \\
\hline & & & Drawbacks & B.1.10 - B.1.14 \\
\hline & \multirow{3}{*}{ Affect } & \multicolumn{2}{|l|}{ Liking, interest, and comfort } & B.2.1-B.2.3, B.2.5 \\
\hline & & \multirow{2}{*}{ Confidence } & Understanding idioms & B.2.3, B.2.6 \\
\hline & & & Using idioms & B.2.4, B.2.7 \\
\hline & \multirow{4}{*}{ Behavior } & \multicolumn{2}{|c|}{ Attention to the CM-inspired instruction } & B.3.1 \\
\hline & & \multicolumn{2}{|c|}{ Participation in CM-related activities } & B.3.2 \\
\hline & & \multicolumn{2}{|c|}{ Attempt to apply conceptual metaphors to learning idioms } & B.3.3 - B.3.4 \\
\hline & & \multicolumn{2}{|c|}{ Intention to learn more about conceptual metaphors } & B.3.5 \\
\hline \multicolumn{2}{|l|}{ Suggestions } & \multicolumn{2}{|c|}{ Suggestions for improving the CM-inspired instruction } & B.1 \\
\hline
\end{tabular}

The central part of the questionnaire was section $B$, which addressed the research question of this study. Most questions in this section were designed in the format of closed-ended questions rated on a 5-point Likert Scale. The scale in this research ranged from Strongly Agree to Strongly disagree or from Never to Always. The respondents revealed their answers by selecting one of these alternatives for each item. Section B included three sub-sections that were related to three components of attitude, as discussed above. At the end of each sub-section, there was one open-ended question to explore some extra ideas or opinions that the Likert scale might fail to address. Especially, as regards sub-section 2 related to the affective aspect, in addition to four closedended questions, there were two multiple-choice questions with the aim to clarify the respondents' level of confidence in their reception and production of the target idioms after exposing to the treatment.

This set of questionnaires was originally written in English and then translated into Vietnamese - the mother tongue of the student respondents. Only the Vietnamese version of the questionnaire was administered to ensure a full understanding of the questionnaire's contents from the students and their freedom to describe their learning experience and their opinions about the treatment.

\subsubsection{Interview}

Eleven students volunteered to be interviewed after completing the questionnaire. The interview questions revolve around the three components of attitude and the students' suggestions for further improvement of the teaching method. To encourage twoway communication and to facilitate comprehensive discussions on the research topic, the researcher conducted semi-structured interviews with four guided open-ended questions:

- What are the benefits and drawbacks of the application of conceptual metaphors to teaching English idioms?

- How did you feel when you were instructed to use conceptual metaphors to learn idioms? Why?

- Do you want to learn more about conceptual metaphors to better understand the meanings of English idioms in particular and English vocabulary in general? Why (not)?

- What is your suggestion for the improvement of this cognitive approach?

For each of the student's responses, the researcher encouraged them to elaborate their answers and provide explanations and examples from their own experience, which could not be done when conducting the questionnaire. Each interview lasted approximately half an hour and the language used throughout the interview was Vietnamese.

\subsection{Data coding and analysis}

The data obtained from the selected-response items were coded and processed via SPSS version 20, whist the free-form responses were grouped according to main ideas and themes. Descriptive statistics were employed in the current study, with frequencies and percentages reported in tables for discussion and interpretation.

\section{Results and Discussion}

This section reports and discusses the results collected from the questionnaire and the interview regarding the students' attitudes towards the employment of conceptual metaphors in teaching English idioms. 


\subsection{Perceptions on the benefits and shortcomings of conceptual metaphors}

Tables 4 and 5 reveal the students' perception of the benefits and drawbacks of applying conceptual metaphors to teaching idioms. This theme is in accord with the first main component of attitude, which is the cognitive aspect.

Table 4. The students' opinions on the benefits of the CM-inspired instruction

\begin{tabular}{|c|c|c|c|c|c|c|}
\hline \multicolumn{2}{|l|}{ The CM-inspired instruction assisted the students in... } & $\begin{array}{l}\text { Strongly } \\
\text { disagree }\end{array}$ & Disagree & Uncertain & Agree & $\begin{array}{l}\text { Strongly } \\
\text { agree }\end{array}$ \\
\hline \multirow{2}{*}{$\begin{array}{l}\text { B.1.1 activating prior knowledge of a familiar physical } \\
\text { phenomenon to understand an unfamiliar abstract } \\
\text { concept. }\end{array}$} & Count & 0 & 0 & 15 & 82 & 9 \\
\hline & $\%$ & 0.0 & 0.0 & 14.1 & 77.4 & 8.5 \\
\hline \multirow{2}{*}{ B.1.2 visualizing the target idioms in their mind. } & Count & 0 & 9 & 38 & 53 & 6 \\
\hline & $\%$ & 0.0 & 8.5 & 35.8 & 50.0 & 5.7 \\
\hline \multirow{2}{*}{$\begin{array}{l}\text { B.1.3 understanding the link between language and } \\
\text { human thoughts/behaviors. }\end{array}$} & Count & 0 & 0 & 13 & 75 & 18 \\
\hline & $\%$ & 0.0 & 0.0 & 12.3 & 70.7 & 17.0 \\
\hline \multirow{2}{*}{$\begin{array}{l}\text { B.1.4 predicting the meanings of the target idioms } \\
\text { correctly. }\end{array}$} & Count & 0 & 6 & 15 & 66 & 19 \\
\hline & $\%$ & 0.0 & 5.7 & 14.1 & 62.3 & 17.9 \\
\hline \multirow{2}{*}{$\begin{array}{l}\text { B.1.5 gaining a deep understanding of the meanings } \\
\text { of the taught idioms. }\end{array}$} & Count & 0 & 0 & 10 & 66 & 30 \\
\hline & $\%$ & 0.0 & 0.0 & 9.4 & 62.3 & 28.3 \\
\hline \multirow{2}{*}{ B.1.6 learning idioms systematically. } & Count & 0 & 0 & 18 & 65 & 23 \\
\hline & $\%$ & 0.0 & 0.0 & 17.0 & 61.3 & 21.7 \\
\hline \multirow{2}{*}{$\begin{array}{l}\text { B.1.7a remembering the meaning of the taught idioms } \\
\text { effectively. }\end{array}$} & Count & 0 & 0 & 9 & 67 & 30 \\
\hline & $\%$ & 0.0 & 0.0 & 8.5 & 63.2 & 28.3 \\
\hline \multirow{2}{*}{$\begin{array}{l}\text { B. } 1.7 b \text { remembering the form of the taught idioms } \\
\text { effectively. }\end{array}$} & Count & 0 & 33 & 19 & 51 & 3 \\
\hline & $\%$ & 0.0 & 31.1 & 18.0 & 48.1 & 2.8 \\
\hline \multirow{2}{*}{ B.1.8 improving their critical thinking. } & Count & 0 & 0 & 21 & 69 & 16 \\
\hline & $\%$ & 0.0 & 0.0 & 19.8 & 65.1 & 15.1 \\
\hline \multirow{2}{*}{ B.1.9 learning about the culture of the target language. } & Count & 0 & 6 & 21 & 66 & 13 \\
\hline & $\%$ & 0.0 & 5.7 & 19.8 & 62.2 & 12.3 \\
\hline
\end{tabular}

As indicated in Table 4, a large percentage of the students showed their agreement on the benefits of the cognitive approach. No students showed strong opposition against any item, and a small minority disagreed with some stated benefits. The extent of agreement, though considerable as compared to disagreement, was diverse among the items. Crucially, slightly over $90.0 \%$ of the respondents reported that the $\mathrm{CM}$-inspired instruction greatly facilitated their understanding and retention of idiomatic meanings (Items B.1.5, B.1.7a). More than four-fifths of the respondents felt that the instruction could help them take advantage of prior knowledge to understand unfamiliar abstract concepts (85.9\%), discover the link between language and human thoughts/behaviors (87.7\%), and learn the target idioms more systematically (83.0\%) (Items B.1.1, B.1.3, B.1.6). A large majority of the students also agreed that learning about conceptual metaphors could help them predict idiomatic meanings more effectively (80.2\%), develop their thinking skills (80.2\%) and improve their knowledge of L2 culture (74.5\%) (Items B.1.4, B.1.8, B.1.9).

There are four major reasons for the success of this approach, which were disclosed via the participants' responses to the questionnaire as well as the interview in this study. Firstly, with the CM-inspired instruction, the students had the opportunity to learn idioms in a more systematic way due to the fact that idiomatic expressions are categorized not only in topics but also in metaphorical themes. According to Gairns and Redman (1986), systematic organization forms the basis for effective long-term retention. Secondly, the cognitive approach facilitates the students' understanding of the semantic motivation underlying the target expressions, thus allowing them to view idioms as meaningful parts of certain structured systems rather than discrete and isolated pieces of language. Thirdly, the CM-inspired instruction is rich in images as conceptual metaphors are grounded in bodily experience and in social and cultural practices; these mental images, together with the verbal forms of the target idioms, can improve the learners' comprehension and retention. This explanation is supported by the Dual Coding Theory, which asserts that information stored mentally in both visual and verbal codes is likely to be better comprehended and retrieved than information stored in only one code (Paivio \& Clark, 1991). Lastly, the CM-oriented instruction encourages the learners to be mentally active, thereby improving their memory of the target lexis. This view is supported by the Levels-of-Processing Theory initially proposed by Craik and Lockhart (1972). As the CM-oriented instruction aims to provide learners with a thorough explanation of the target lexis, it may take a longer time as well as more steps to process all the received information. Specifically, the students are guided to activate prior knowledge about a concrete concept to understand an abstract concept and associate the verbal information with a mental image. Such mental elaboration of the input is at a deeper level than the superficial processing in blind memorization, which results in more efficient and durable retention. 
The least approved benefits of the $\mathrm{CM}$-inspired instruction are the facilitation of the learners' visualization of the target idioms (55.7\%) and their retention of the idiomatic form (50.9\%) (Items B.1.2, B.1.7b). Especially, 31.1\% of the students did not think that the CM-inspired instruction could facilitate their recall of idiomatic forms (Item B.1.7b). This was also the item that got the highest percentage of disagreement among the benefits stated in the questionnaire. In terms of the interviews, four students out of eleven were uncertain whether any mental images of the idioms were built up thanks to the knowledge of conceptual metaphors, and one student even denied this benefit of the $\mathrm{CM}$-inspired instruction. This finding seems to contradict Boers and Lindstromberg (2008) who asserted that the explicit instruction of the conceptual metaphors underlying the metaphorical expressions could possibly stimulate the learners' visualization of the input by activating their prior knowledge of the source domain. Such a process is believed to allow dual coding of information, leading to the improvement of the learner's comprehension and memory of the target language. However, the responses from the participants in this study disclose that not all students had the same inclination towards imagery processing. A possible explanation for this might lie in the difference in their cognitive styles. Visual learners, or high imagers, might be more susceptible to the $\mathrm{CM}$-inspired instruction which is essentially rich in imagery since these learners, according to Brown (2007), are more inclined to think in images and learn best with visual images. On the contrary, those with low imaging processing were not liable to form mental pictures to be stored in memory together with the verbal form of the idioms during the instruction, thus hindering the dual coding process. This might be the reason why a noticeable number of the students felt uncertain about or even denied the use of mental images during the instruction stage. However, this does not necessarily mean that low imagers are unlikely to take advantage of conceptual metaphors to better their comprehension and retention of idiomatic language. This will be discussed in Section 5.

Overall, though there were some items that were disagreed to some extent, most respondents seemed to approve of the useful effects of the CM-inspired instruction on their idiomatic acquisition and their learning skills in general. As every issue has two sides, the drawbacks of this type of instruction were also taken into consideration. The results are presented in the table below.

Table 5. The students' opinions on the drawbacks of the CM-inspired instruction

\begin{tabular}{|l|l|l|l|l|l|l|}
\hline \multirow{2}{*}{ The CM-inspired instruction... } & $\begin{array}{l}\text { Strongly } \\
\text { disagree }\end{array}$ & Disagree & Uncertain & Agree & $\begin{array}{l}\text { Strongly } \\
\text { agree }\end{array}$ \\
\hline $\begin{array}{l}\text { B.1.10 caused some difficulty at the } \\
\text { beginning since it was new. }\end{array}$ & Count & 3 & 6 & 9 & 76 & 12 \\
\cline { 2 - 8 } & $\%$ & 2.8 & 5.7 & 8.5 & 71.7 & 11.3 \\
\hline \multirow{3}{*}{ B.1.11 was complicated. } & Count & 6 & 66 & 12 & 21 & 0 \\
\cline { 2 - 8 } & $\%$ & 5.7 & 62.3 & 11.3 & 19.8 & 0.0 \\
\hline \multirow{2}{*}{ B.1.12 was time-consuming. } & Count & 4 & 54 & 9 & 39 & 0 \\
\cline { 2 - 8 } & $\%$ & 3.8 & 50.9 & 8.5 & 36.8 & 0.0 \\
\hline \multirow{2}{*}{ B.1.13 increased memory load. } & Count & 7 & 48 & 15 & 36 & 0 \\
\cline { 2 - 8 } & $\%$ & 6.6 & 45.3 & 14.1 & 34.0 & 0.0 \\
\hline \multirow{3}{*}{$\begin{array}{l}\text { B.1.14 distracted attention from the form } \\
\text { of the target idioms. }\end{array}$} & Count & 1 & 56 & 18 & 31 & 0 \\
\cline { 2 - 7 } & $\%$ & 0.9 & 52.9 & 17.0 & 29.2 & 0.0 \\
\hline
\end{tabular}

Table 5 is quite revealing in several ways. The responses from the participants were more various, as compared to the items in the previous table. $83 \%$ of the students admitted that they had difficulty following the instruction at the beginning of the experiment (Item B.1.10). The reason lay in their initial unfamiliarity with the concept of conceptual metaphor and how to apply it to their learning. However, after a five-week treatment, there seemed to be a marked change in their viewpoint on the CM-inspired instruction and its effect, which can be seen in their responses to the four following items. Nearly $70 \%$ of the participants did not think that the instruction was too complicated for them to follow (Item B.1.11). In the same vein, more than half of those surveyed (54.7\%) asserted that it did not take a great amount of time to comprehend conceptual metaphors and employ them to learn idioms (Item B.1.12). Surprisingly, a similar percentage of the respondents (51.9\%) even claimed that the knowledge of conceptual metaphors did not increase the burden on their memory (Item B.1.13). As to its effect on the form retention, more than half of the subjects reported that the $\mathrm{CM}$-inspired instruction did not cause a distraction to their acquisition of the idiomatic forms (53.7\%) (Item B.1.14). This finding is in agreement with item B.1.7b, concerning the effect of CM-inspired instruction on the students' retention of idiomatic form.

According to the interviewees, learning idioms with the $\mathrm{CM}$-inspired instruction appeared to be more mentally demanding but turned out to be rewarding in the long run. Besides, they said that after five lessons being carefully instructed how to use conceptual metaphors to learn idioms, they were gradually becoming accustomed to this learning method and did not find it difficult anymore. Specifically, more than half of the interviewees did not think that the addition of CM information increased the burden on their memory in an attempt to learn the target idioms. Interestingly, three students even pointed out that there were some common conceptual metaphors between English and Vietnamese, such as HAPPY IS UP / SAD IS DOWN, ANGER IS FIRE, LIFE IS A JOURNEY, 
etc., and therefore, they were easy to understand and apply to interpret idiom meaning. In other words, in these cases, the CMinspired instruction seemed not to provide any new information to the students, but simply activate what they had already had in their minds. This result may be explained by the pervasiveness of metaphors in daily language and thought as well as their universality among cultures. For decades, Lakoff and his advocates have demonstrated that metaphors are omnipresent in everyday life and they are not simply a matter of language but a matter of thought and reason (Lakoff \& Johnson, 1980; Lakoff, 1993; Gibbs, 1994; Kövecses, 2002). Therefore, it is reasonable to infer that the knowledge of conceptual metaphors is pre-existing in the students' minds; in other words, metaphors are part of their world knowledge. Thus, when the students were taught about conceptual metaphors shared between $\mathrm{L} 1$ and $\mathrm{L} 2$ cultures during the instruction stage, they might have had a feeling of familiarity with them, at least subconsciously. This may explain why nearly $52 \%$ of the subjects disagreed that the CM-inspired instruction was burdensome for their memory, and almost $70 \%$ did not think that it was difficult to understand.

However, there were cases when the universality of some conceptual metaphors can be found only at a generic level, not at a specific level. Perhaps in this study, it was the difference at the specific level that caused certain difficulties to the EFL students. For instance, in the conceptual metaphor LIFE IS A GAMBLING GAME, actions in life are conceived as gambles, and the consequences of these actions are understood as winning or losing the games, as in If you play your cards right, the job could be yours when she leaves. This is generally a familiar concept to the students in this study, and the idiom play one's cards right is not difficult to understand as playing cards are also common in Vietnam, which facilitates the inference of its figurative meaning. However, there are different types of gambling, some of which are unfamiliar to Vietnamese culture, as in the case of Some people trying to pass the buck whenever they can. According to Ammer (1997), the expression pass the buck dates back to the mid-1800s when poker became very popular in America. In order to avoid cheating, the deal changed hands during sessions, and a buck, i.e. a knife with the handle made of buck's horn, was passed to the next player to remind him of his turn to deal responsibly ('Pass the buck', n.d.). Since this etymological information was new to most of the students, it took them time to absorb the information, find out the correspondence between the source domain and the target domain, and finally deduce the figurative meaning of the target idiom. Perhaps because of this case and other similar ones, nearly $37 \%$ of the participants thought that the CM-inspired instruction might be somewhat lengthy (Item B.1.12), almost 20\% found it complicated (Item B.1.11), and 34\% reported that the instruction added more weight to their memory in addition to the main content of the lesson (Item B.1.13). As compared to rote learning, the CMinspired instruction appears to be more demanding in terms of thinking, visualizing, and inferring, but all the efforts turn out to be rewarding as the majority of the students interviewed believed that their knowledge of conceptual metaphors would enhance their retention of the target idioms, especially in the long terms. This finding is in good agreement with Pham and To (2019), which shows that the students who learned idioms with the $\mathrm{CM}$-inspired instruction outperformed their counterparts who were instructed in the traditional method in terms of both reception and production of the target idioms even five weeks after the instruction.

Another drawback of the $\mathrm{CM}$-inspired instruction is that it might not directly foster the retention of the precise lexical makeup of the target idioms. Approximately $30 \%$ of the participants agreed with this claim (Item B.1.7b), and a similar percentage of the students even thought that the semantic elaboration of conceptual metaphors could divert their attention from the form of the target idioms (Item B.1.14). This distraction may be due to the picture superiority effect as the CM-inspired instruction is rich in imagery. As Stenberg (2006) explained, when words are presented in company with pictures, it is the pictures that are better encoded and recollected as opposed to words. In addition, pictures tend to be associated more easily and instantly with concepts than words. A closer examination of the student's answers in the interview also revealed that, in some cases, the students remembered the concepts explained with the Conceptual metaphors rather than the exact constituent words or the lexical composition of the whole idioms. For example, they tended to remember the wrong phrase to flip the top or to flip the cover instead of to flip the lid, or remember the incorrect expression to add oil to the fire instead of to add fuel to the fire. Despite its semantic orientation, more than half of the questionnaire respondents, however, believed that the CM-inspired instruction somewhat promoted their retention of form.

The reason for this effect is not clear, but it might also be related to the Dual Coding Theory and the guessing task during the instruction. The fact that pictures are relatively easier to recall due to the picture superiority effect does not necessarily mean that their corresponding linguistic forms cannot be stored and retrieved. Presumably, if the images or the concepts formed by the elaboration of conceptual metaphors are not particularly complicated or bizarre, they will not divert the learner's attention from the form of the idioms, and therefore they may leave them with more time to process the verbal information. As "both metaphorical language and thought arise from the basic bodily (sensorimotor) experience of human beings" (Kövecses, 2002, p. $x$ ), most concepts that the CM-inspired instruction discusses are shared among cultures and therefore become pre-existing knowledge. This means, in most cases, the CM-inspired instruction and what it discusses or creates in the learner's mind tends not to be so compelling or perplexing that it might capture all his/her attention, leaving them no time for committing the idiomatic form to memory. In other words, though the CM-inspired instruction did not directly elaborate the lexical makeup of the target idioms, it could facilitate the dual coding process and assist learners with mental images as an aid for form elicitation. Another factor that led to the students' belief that the CM instruction can assist their retention of idiomatic forms may be the guessing task in the 
teaching procedure. During the instruction stage, the students were allowed to take advantage of the literal meaning of the key constituent words of the target idioms to infer their figurative meanings. This task might have stimulated the students to pay closer attention to the lexical composition of the idioms, resulting in their better performance. In a word, the students' retention of idiomatic form seemed to be a by-product of the $\mathrm{CM}$-inspired instruction, which was more meaning-focused.

Overall, the major problem of the CM-inspired instruction could be found in the students' initial unfamiliarity with the notion of $\mathrm{CM}$ and the retention of idiomatic form. However, their sufficient exposure to the treatment over time seemed to help them grasp the idea of conceptual metaphor quicker and make the most use of the instruction to learn idioms more vividly, meaningfully, and systematically without spending too much time or overloading their memory.

\section{2. Feelings towards the application of conceptual metaphors to teaching idioms}

Following the examination of the cognitive component of attitude was the investigation of the affective component. The focus of this sub-section was, therefore, shifted to the subjects' emotional response to the CM-inspired instruction.

Table 6. The students' feelings towards the application of conceptual metaphors to teaching idioms

\begin{tabular}{|c|c|c|c|c|c|c|}
\hline \multicolumn{2}{|l|}{ The students... } & $\begin{array}{l}\text { Strongly } \\
\text { disagree }\end{array}$ & Disagree & Uncertain & Agree & $\begin{array}{l}\text { Strongly } \\
\text { agree }\end{array}$ \\
\hline \multirow{2}{*}{$\begin{array}{l}\text { B.2.1 found the } \mathrm{CM} \text {-inspired instruction } \\
\text { interesting. }\end{array}$} & Count & 0 & 6 & 5 & 61 & 34 \\
\hline & $\%$ & 0.0 & 5.7 & 4.7 & 57.5 & 32.1 \\
\hline \multirow{2}{*}{$\begin{array}{l}\text { B.2.2 felt comfortable when learning idioms with } \\
\text { the help of CM-inspired instruction. }\end{array}$} & Count & 0 & 15 & 18 & 58 & 15 \\
\hline & $\%$ & 0.0 & 14.2 & 17.0 & 54.7 & 14.1 \\
\hline \multirow{2}{*}{$\begin{array}{l}\text { B.2.3 felt confident in their ability to understand } \\
\text { the idiomatic meaning with the help of CM- } \\
\text { inspired instruction. }\end{array}$} & Count & 0 & 9 & 15 & 51 & 31 \\
\hline & $\%$ & 0.0 & 8.5 & 14.2 & 48.1 & 29.2 \\
\hline \multirow{2}{*}{$\begin{array}{l}\text { B. } 2.4 \text { felt confident in my ability to use idioms with } \\
\text { the help of } C M \text {-inspired instruction. }\end{array}$} & Count & 0 & 15 & 36 & 43 & 12 \\
\hline & $\%$ & 0.0 & 14.2 & 34.0 & 40.5 & 11.3 \\
\hline
\end{tabular}

In general, the respondents had a positive feeling towards the CM-inspired instruction. Specifically, nearly $90 \%$ took an interest in the instruction due to its engaging content (Item B.2.1). Almost 70\% felt relaxed during the instruction (Item B.2.2). Nearly fourfifths (77.3\%) expressed their confidence in comprehending the idioms, while slightly more than half of them (51.8\%) felt confident in using what they had learned.

The students' confidence was also shown through their self-assessment of their reception and production of the target idioms in items B.2.5 and B.2.6.

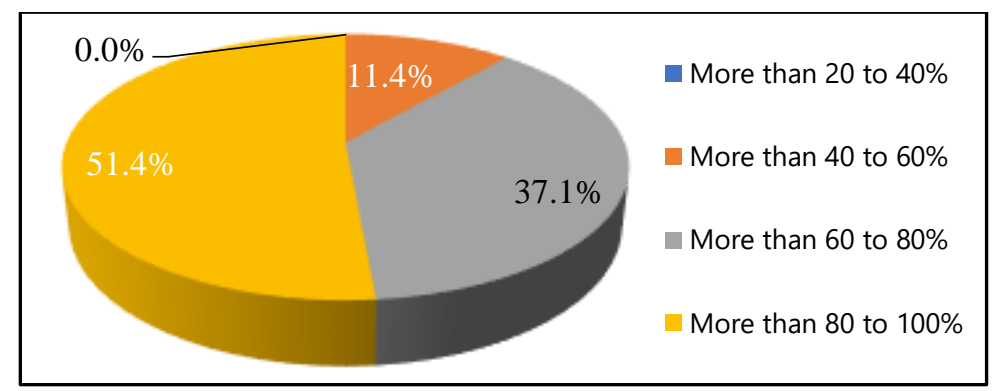

Figure 1. The students' self-assessment of their understanding of the introduced idioms after the course (Item B.2.5)

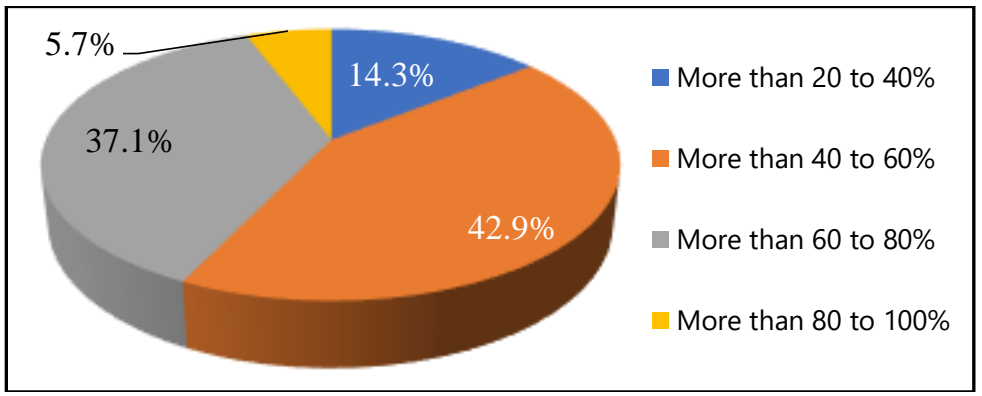

Figure 2. The students' self-assessment of their ability to use the introduced idioms after the course (Item B.2.6) 
As can be seen from Figures 1 and 2, the subjects' evaluation of their receptive knowledge of idioms was more positive. Whereas the highest proportion of their self-assessment on idiom reception could be found in the category of more than 80 to $100 \%$ (51.4\%), this category accounted for the lowest proportion in the case of their productive knowledge of the idioms (5.7\%). Besides, only $11.4 \%$ of the students claimed that they could understand from 40 to $60 \%$ of the idioms and no one reported less than that. On the contrary, almost $43 \%$ of the students believed that they were able to use 40 to $60 \%$ of the idioms, which also constituted the largest proportion regarding idiom production, and there were even more than $14 \%$ that reported less than that. In sum, after the treatment, the students were able to understand more idioms than they could actually use.

Since idioms are "indivisible units whose components cannot be varied or varied only within definable limits" (Fernando, 1996, p. $30)$, it is certain that the students in this study faced great difficulty in recollecting the precise composition of these multi-word expressions, though they could fully understand their meaning. This result accords with Nation (2001)'s and Thornbury (2002)'s observation, which showed that $\mathrm{L} 2$ learners' receptive knowledge of vocabulary tends to exceed their productive knowledge and generally precede it. In this case, the students might understand more idioms than they could really use, and they might even understand them before being capable of uttering them.

\subsection{Reactions to the CM-inspired instruction in teaching idioms}

In addition to cognitive and affective components, the behavioral component is also worth considering for a detailed insight into the subjects' attitude towards the CM-inspired instruction.

Table 7. The students' reactions to the CM-inspired instruction

\begin{tabular}{|c|c|c|c|c|c|c|}
\hline \multicolumn{2}{|l|}{ The students... } & Never & Rarely & Sometimes & Often & Always \\
\hline \multirow{2}{*}{$\begin{array}{l}\text { B.3.1 paid close attention to the } \mathrm{CM} \text {-inspired } \\
\text { instruction. }\end{array}$} & Count & 0 & 0 & 15 & 66 & 25 \\
\hline & $\%$ & 0.0 & 0.0 & 14.2 & 62.3 & 23.6 \\
\hline \multirow{2}{*}{$\begin{array}{l}\text { B.3.2 actively engaged in-class activities related to } \\
\text { idiom learning with the help of } C M \text {-inspired } \\
\text { instruction. }\end{array}$} & Count & 0 & 0 & 21 & 55 & 30 \\
\hline & $\%$ & 0.0 & 0.0 & 19.8 & 51.9 & 28.3 \\
\hline \multirow{2}{*}{$\begin{array}{l}\text { B.3.3 tried to apply the knowledge of conceptual } \\
\text { metaphors to learn the target idioms in class. }\end{array}$} & Count & 0 & 0 & 21 & 63 & 22 \\
\hline & $\%$ & 0.0 & 0.0 & 19.8 & 59.4 & 20.8 \\
\hline \multirow{2}{*}{$\begin{array}{l}\text { B.3.4 tried to apply the knowledge of conceptual } \\
\text { metaphors outside the classroom to learn new idioms } \\
\text { found in books, newspapers, movies, etc. }\end{array}$} & Count & 6 & 15 & 67 & 18 & 0 \\
\hline & $\%$ & 5.7 & 14.2 & 63.2 & 16.9 & 0.0 \\
\hline \multirow{2}{*}{$\begin{array}{l}\text { B.3.5 want to learn more idioms under the CM- } \\
\text { inspired instruction in the future. }\end{array}$} & Count & 0 & 0 & 27 & 56 & 23 \\
\hline & $\%$ & 0.0 & 0.0 & 25.5 & 52.8 & 21.7 \\
\hline
\end{tabular}

Due to their positive opinions and feelings towards the CM-inspired instruction, the majority of the students tended to react favorably to the instruction. Four-fifths of those surveyed, or slightly more than that, reported on close attention to the lesson, frequent participation in CM-related activities, and application of conceptual metaphors to learn idioms during the teaching stage (Items B.3.1, B.3.2, and B.3.3). Interestingly, approximately three-quarters of the students, despite the shortcomings of this instruction, showed their eagerness to continue to learn idioms with this strategy after the treatment (Item B.3.5). In fact, their responses to the questions in this section were rather consistent with one another, with "often" as the most common choice, "always" the second, and "sometimes" the third, except in the case of item B.3.4.

There are several possible explanations for the students' positive feelings and reactions towards the treatment. Most interviewees pointed out that, thanks to the elaboration of conceptual metaphors, they are aware that idiomatic language is not arbitrary and therefore, blind memorization is not the only way to acquire idioms. Revealing the motivation behind a series of idioms has opened up a path to insightful learning in which individual expressions are parts of a meaningful network. In addition, the knowledge of conceptual metaphors also provided them with a new strategy, in addition to the use of context, to discover the figurative meanings of unfamiliar idiomatic phrases. The interviewed students also expressed their satisfaction, revealing that the CM-inspired instruction has indeed lightened the burden of learning lists of idioms by rote with its systematization. As the students gained a better insight into the nature of idiomatic language, they were more assured about their understanding and use of the taught idioms. These reasons explain why a significant proportion of the respondent reported that they felt interested, comfortable, and self-confident when conceptual metaphors were used as a strategy to learn idioms (Items B.2.1, B.2.2, B.2.3, and B.2.4). In-depth interview data reveal another possible reason for the students' positive attitude towards the instruction, which lies in its problemsolving nature. In the instruction stage, the students were given chances to apply prior knowledge to better comprehend the new concept, find correspondences between source and target domains, formulate hypotheses about the figurative meaning of the target idioms and then receive feedback from the teacher. These activities seemed to be intellectually challenging and motivating 
to the students as a very large majority reported that they paid close attention to the instruction and actively took part in metaphorrelated activities (Item B.3.1 and B.3.2).

It is also worth discussing whether the $\mathrm{CM}$-inspired instruction was beneficial to the students in learning new idioms outside the classroom. The responses to item B.3.4 reveal that the students tended to employ conceptual metaphors less frequently without the teacher's guidance to acquire new idioms after the lesson (Item B.3.4). Even $20 \%$ of the students claimed that they never or rarely applied conceptual metaphors outside the classroom to learn new idioms found in books, newspapers, or movies, though they were eager to use them inside the classroom. There might be two reasons for this finding. Firstly, the interview data reveal that the five-week instruction time seemed to be too short to provide the learners with a sufficient number of common conceptual metaphors so that they could analyze the motivation behind new idioms that they encountered outside the classroom. Secondly, all the interviewees agreed that they need a lot of guidance and direct feedback from the teacher in order to apply conceptual metaphors effectively to learning idioms. Though the knowledge of conceptual metaphors provides useful clues to their analysis of the figurative meanings of the expressions, it does not necessarily guarantee correct interpretations to all situations, especially in the case of cross-cultural differences. This observation is consistent with Skoufaki (2008)'s finding, which disclosed that $75 \%$ of the students' guesses in the CM group would have required corrective feedback from the teacher. Therefore, the teacher's explicit instruction and feedback, especially in the initial stages, are necessary for the students to make the most use of conceptual metaphors before they can employ them autonomously to learn new idioms comprehensively. In fact, it may be unrealistic to require the students to be able to provide detailed mappings between source and target domains and explicate their correspondences for better understanding whenever encountering new idioms. What is really important is their awareness that language is not arbitrary and their confidence that there is a more effective strategy than blind memorization to acquire idiomatic language. Heightened language awareness and confidence, complemented by explicit CM-inspired instruction and related activities, are expected to be helpful in developing the learner's idiomatic competence over time.

\subsection{Suggestions for further improvement}

Several respondents to the questionnaire and interviewees did not provide any suggestions as they were apparently satisfied with the application of conceptual metaphors to idiom teaching. However, about one-quarter of the questionnaire respondents did put forward the idea of using pictures as an aid to the instruction; some interviewees also added that the lesson duration should be longer for better acquisition and there should be more activities to assist students' retention of idiomatic form.

Based on the responses to the questionnaire and the interview, it can be concluded that the students' attitudes towards the CMinspired instruction were highly positive. The instruction brought various benefits for EFL learning in general and idiomatic acquisition in particular; most of them were appreciated by a large number of students in this study. Though there were a few drawbacks in terms of structural elaboration, image processing, and learners' initial unfamiliarity with the application of conceptual metaphors, the results of this study reveal that the benefits of the CM-inspired instruction far outweighed its drawbacks in facilitating idiom acquisition. Moreover, there are possible solutions to these shortcomings, as presented in the following section.

\section{Possible ways to improve the $\mathrm{CM}$-inspired instruction}

As discussed above, the CM-inspired instruction tends to be rich in imagery; nevertheless, not all students have an equally strong tendency to form mental images in information processing due to different cognitive styles. Therefore, the teacher may use actual pictures rather than eliciting mental images to assist low imagers in dually coding the target information. This solution is in agreement with $37.1 \%$ of the students who were in favor of real pictures as a complement to the CM-inspired instruction.

Too many stimuli, however, may be counterproductive. According to Boers, Lindstromberg, Littlemore, Stengers, and Eyckmans (2008), the use of real pictures may have a distractive effect, especially in the case of long and complex expressions. In order to reduce this effect and the tendency of picture superiority, the use of pictures should be limited and the content of the pictures must be clear, simple, and relevant to the meaning of the idioms. Since idioms can be categorized according to conceptual metaphors, those in the same category are related to each other in a meaningful network. Thus, instead of using one picture for each idiom, one picture can be used for two or three related idioms or even for the whole category. This technique is expected to reduce memory load for imagery, save more time for the learner to process verbal information, and commit it to memory. In a word, this technique may further facilitate dual coding of information and, at the same time, lessen the distractive effect of pictures, resulting in better retention and production of the target idioms.

As the CM-inspired instruction is more meaning-focused, other activities related to structural elaboration are necessary for the retention of idiomatic form. Besides exercises aimed at eliciting the precise lexical makeup of idioms, introducing the learners to the phonological motivation behind the target phrases is also worth considering. According to Boers and Lindstromberg (2008c), the lexical composition of several (semi-)fixed phrases is explicable in terms of alliteration and assonance (See sub-section 2.1.5.2). In fact, some common mistakes in word selection made by the students in this study can be rectified via this technique. For example, it is hard to explain, via semantic elaboration, why the standard phrase is added fuel to the fire rather than add oil to the 
fire as in the Vietnamese equivalent, or why people say flip your lid rather than flip your top or flip your roof though "lid," "top" and "roof" are nearly synonymous. Phonological motivation may be helpful in this case as it seems that in word combinations "euphonious word strings are preferred over same meaning but non-euphonious word strings" (Boers \& Lindstromberg, 2008c, p. 330). Thus, the teacher can explain to the students that "fuel" was selected rather than "oil" in the idiom add fuel to the fire because it alliterates with the word "fire" at the end of the phrase. Specifically, both "fuel" and "fire" share the same voiceless labiodental consonant / $f$ / at the initial position and sound pleasant when standing together. Likewise, in the idiom flip your lid, "flip" rhymes with "lid" which has the same short, lax, high, front, and slightly spread vowel /I/. Similar cases can be found in several idioms taught in this study: a heavy heart, fan the flames, bite the bullet, be going great guns, pass the buck, gain ground on, set your sights on, follow in one's footsteps (alliteration); seventh heaven, a dead-end, reach boiling point, spin one's wheels, down in the mouth, a flash in the pan (assonance). Hopefully, this technique can help the students better understand the motivation, i.e. both semantic and phonological, behind the target idioms and later, serve as a mnemonic device for the students to recall the precise components used in these idioms for production.

\section{Conclusion}

The findings of this study reveal that the students generally showed their highly favorable attitude towards the CM-inspired instruction, though the instruction itself exposed some shortcomings that need to be dealt with. There are four important reasons for the success of this technique, including systematic and insightful learning, dual-coding process, and deep processing level. In general, this study supported the Conceptual Metaphor Theory and the cognitive-linguistic approaches to teaching vocabulary. As regards its drawbacks, two possible solutions were proposed with their theoretical background based on previous work, including the addition of real pictures as an extra stimulus for the dual coding process and the explanation of the phonological motivation for better semantic and structural elaboration during the CM-inspired instruction.

Notwithstanding these drawbacks, the article does make important contributions to the teaching of idioms in several aspects. Firstly, the study provides a systematic and insightful presentation of English idioms, allowing students to learn these "notoriously difficult" expressions more easily and effectively. Secondly, the findings of the study suggest that, as an instructor, advisor, and facilitator, the teacher should try new ways to elaborate the meaning of idiomatic expressions to the students rather than simply encourage rote learning, especially when plausible explanations are available. This prevents the learners from the bad habit of blind memorization and from the wrong assumption that idiom learning is a tedious, demanding task. Last but not least, the results of this study have confirmed the effectiveness of applying conceptual metaphors to teaching English idioms not from the teachers' beliefs or the test results as in previous studies, but from the perspectives of EFL students themselves which are also of great importance in the success of a teaching method.

Despite the researcher's determined attempt, this work clearly has some limitations found in its application to idiom teaching and the scope of the study itself. It must be acknowledged that not all idioms appear to lend themselves equally well to the CMinspired instruction. Certain idioms such as fit as a fiddle, to have a green thumb, and spick and span might be too opaque to capture under any conceptual metaphors. In other words, the CM-inspired instruction seemed to be more applicable to transparent and semi-transparent idioms. Besides, owing to the constraints of time and resources, only sixty idioms and ten underlying conceptual metaphors were collected for the teaching material. Such a limited range of idioms and metaphors only allowed the researchers to touch on a few aspects of cross-cultural universality and variation in metaphorical language, which are also key issues in cognitive linguistics.

Based on these limitations, further investigation and experimentation are strongly recommended. One of the topics that deserve more investigation is cross-cultural universality and variation in metaphorical language and thought. As Boers, Demecheleer, and Eyckmans (2004) pointed out different linguistic communities may have different idiomatic expressions due to different cultures and histories. Even if two languages share similar conceptual metaphors, the forms, or the surface structures, of the idioms motivated by these metaphors are often different (Kövecses, 2002). Such a distance between the learner's L1 and L2 remains an obstacle in the path of idiomatic mastery. Therefore, comparison and contrast of idiomatic expressions in L1 and L2 at the conceptual and linguistic levels should help students discover the similarities and differences between the two languages, encourage positive transfer, and avoid negative interference from L1, thereby facilitating their idiom acquisition. A deeper understanding of the universality and variability in metaphorical language and thought across different cultures may also result in better teaching materials and classroom activities, which aim to raise the learner's awareness of different source domains in different cultures.

In brief, within its limited scope, the study has just focused on a minor part of the Conceptual Metaphor Theory and its pedagogical application in the EFL context. It is hoped that this study will be a small contribution to the development of the Conceptual Metaphor Theory and its application to the acquisition of vocabulary in general and idioms in particular.

Funding: This research received no external funding. 
Conflicts of Interest: The authors declare no conflict of interest

\section{References}

[1] Ammer. C. (1997). The American Heritage ${ }^{\circledR}$ Dictionary of Idioms. Houghton Mifflin.

[2] Boers, F., Eyckmans, J., \& Stengers, H. (2007). Presenting figurative language with a touch of etymology: more than mere mnemonics? Language Teaching Research, 11(1), 43-62. https://doi.org/10.1177/1362168806072460

[3] Boers, F., \& Lindstromberg, S. (2008). Applications of cognitive linguistics: Cognitive linguistic approaches to teaching vocabulary and phraseology. Mouton de Gruyter.

[4] Boers, F., Lindstromberg, S., Littlemore, J., Stengers, H., \& Eyckmans, J. (2008). Variables in the mnemonic effectiveness of pictorial elucidation. In F. Boers \& S. Lindstromberg (Eds.), Applications of cognitive linguistics: Cognitive linguistic approaches to teaching vocabulary and phraseology (pp. 189-216). Mouton de Gruyter.

[5] Brenner, G. (2003). Webster's New World American idioms handbook. Wiley Publishing.

[6] Brown, H. D. (2007). Principles of language teaching and learning $\left(5^{\text {th }}\right.$ ed.). Longman.

[7] Celce-Murcia, M. (2008). Rethinking the role of communicative competence in language teaching. In E. Alcón Soler, \& P. Safont Jordà (Eds.), Intercultural language use and language learning (pp. 41-57). Springer.

[8] Chen, Y. (2019). Teaching figurative language to EFL learners: an evaluation of metaphoric mapping instruction. The Language Learning Journal, 47(1), 49-63. https://doi.org/10.1080/09571736.2016.1185798

[9] Craik, F. I. M., \& Lockhart, R. S. (1972). Levels of processing: A framework for memory research. Journal of Verbal Learning and Verbal Behaviour, 11, 671-684. https://doi.org/10.1016/S0022-5371(72)80001-X

[10] Doiz, A. \& Elizari, C. (2013). Metaphoric competence and the acquisition of figurative vocabulary in foreign language learning. Estudios ingleses de lingüística aplicada (ELIA) [English Studies of Applied Linguistics] 13, 47-82.

[11] Fernando, C. (1996). Idioms and idiomaticity. Oxford University Press.

[12] Gairns, R., \& Redman, S. (1986). Working with words: A guide to teaching and learning vocabulary. Cambridge University Press.

[13] Gardner, R. C. (1985). Introduction: Focus on the major issues. In R. C Gardner, Social psychology and second language learning: the role of attitudes and motivation (pp. 1-15). Edward Arnold. http://publish.uwo.ca/ gardner/docs/SECONDLANGUAGE1985book.pdf

[14] Irujo, S. (1986). A piece of cake: Learning and teaching idioms. ELT Journal, 4O(3), 236-242. https://doi.org/10.1093/elt/40.3.236

[15] Kartal, G. \& Uner, S. (2017). The effects of conceptual metaphors on the acquisition of phrasal verbs by Turkish EFL learners. European Journal of Foreign Language Teaching, 2(2), 34-51. https://doi.org/10.5281/zenodo.556421

[16] Khoshniyat, A. S. \& Dowlatabadi, H. R. (2014). Using conceptual metaphors manifested in Disney movies to teach English idiomatic expressions to young Iranian EFL learners. Procedia-Social and Behavioral Sciences, 98(1), 999-1008. https://doi.org/10.1016/j.sbspro.2014.03.510

[17] Kömür, S., \& Çimen, S. S. (2009). Using conceptual metaphors in teaching idioms in a foreign language context. Sosyal Bilimler Enstitüsü Dergisi (ILKE) [Journal of the Institute of Social Sciences (Policy)], 23, 205-222.

[18] Kövecses, Z. (2002). Metaphor: A practical introduction. Oxford University Press.

[19] Lakoff, G. (1993). The contemporary theory of metaphor. In A. Ortony (ed.), Metaphor and thought (2 ${ }^{\text {nd }}$ ed.) (202-251). Cambridge University Press.

[20] Lakoff, G. \& Johnson, M. (1980). The metaphor we live by. University of Chicago Press.

[21] Lakoff, G., \& Turner, M. (1989). More than cool reason: a field guide to poetic metaphor. Chicago University Press.

[22] O'Dell, F. \& McCarthy, M. (2010). English idioms in use (Advanced). Cambridge University Press.

[23] Nation, P. (2001). Learning vocabulary in another language. Cambridge: Cambridge University Press.

[24] Paivio, A. \& Clark, J. M. (1991). Dual coding theory and education. Educational Psychology Review, 3, $233-262$. http://doi.org/10.1007/bf01320076

[25] Pass the buck. (n.d.). In The Phrases Finder. https://www.phrases.org.uk/meanings/pass-the-buck.html

[26] Pérez, R. G. (2018). The development of a metaphoric competence: A didactic proposal of educational innovation. Innovation in Language Learning and Teaching, 1-27. https://doi.org/10.1080/17501229.2018.1466891

[27] Pham, T. B. N. (2017). Teaching English idioms of happiness and sadness through conceptual metaphors in the Vietnamese context. Ho Chi Minh City Open University Journal of Science, 7(1), 94-102.

[28] Pham, T. B. N., \& To, M. T. (2019). The application of conceptual metaphors to teaching English idioms to English-majored students in Viet Nam. Theory and Practice in Language Studies, 9(6), 610-619. http://dx.doi.org/10.17507/tpls.0906.02

[29] Shan, X. (2020). A study of idiom teaching from the perspective of conceptual metaphor. Journal of Contemporary Educational Research, 4(1), 60-64. http://dx.doi.org/10.26689/jcer.v4i1.964

[30] Simpson, R., \& Mendis, D. (2003). A Corpus-based study of idioms in academic speech. TESOL Quarterly, 37(3), 419-442. http://deepblue.lib.umich.edu/bitstream/handle/2027.42/90255/3588398.pdf?sequence $=1$

[31] Skoufaki, S. (2008). Conceptual metaphoric meaning clues in two idiom presentation methods. In F. Boers, \& S. Lindstromberg (Eds.), Applications of cognitive linguistics: Cognitive linguistic approaches to teaching vocabulary and phraseology (pp.101-132). Mouton de Gruyter.

[32] Thornbury, S. (2002). How to teach vocabulary. Pearson Longman.

[33] Tran, H. Q. (2013). Figurative idiomatic competence: An analysis of EFL learners in Vietnam. Language Education in Asia, 4 (1), $23-38$. http://dx.doi.org/10.5746/LEiA/13/N4/I1/A3/Tran

[34] Upadhaya, B., \& Sudharshana, N. P. (2021). Developing conceptual metaphor-based tasks in the teaching and learning of idiomatic expressions. TESOL Journal, 12(2), e560. https://doi.org/10.1002/tesj.560

[35] Wang, X. (2020). Applying cognitive linguistics to second language idiom learning [Doctoral thesis, Victoria University of Wellington]. Victoria University of Wellington. http://hdl.handle.net/10063/9153

[36] Zimbardo, P. G., Ebbesen, E. B. (1970). Influencing attitudes and changing behavior. Addison-Wesley. 